\title{
A REMARKABLE NEW GENUS OF LYGAEIDAE FROM SUMATRA (HEMIPTERA: HETEROPTERA)*
}

\author{
By James A. Slater \\ Department of Zoology and Entomology \\ University of Connecticut
}

Many species of Lygaeidae possess fore femora that are strongly incrassate and armed on the ventral surface with sharp spines. Many workers have assumed that these powerful legs were associated with predatory habits and indeed as recently as 1956 Miller illustrated species of Blissinae (Spalacocoris and Chelochirus) as examples of legs modified for raptoral purposes. However, it has been evident for a long time that this was at best an oversimplification and that very strongly incrassate and heavily spinous legs were known in such subfamilies as the Pachygronthinae and Oxycareninae whose members so far studied are entirely phytophagous, whereas in the predaceous Geocorinae the fore femora are slender and not at all adapted for seizing prey. The enlarged leg is best expressed in the great subfamily Rhyparochrominae where nearly all of the many hundreds of species possess enlarged and ventrally spined fore femora. Putshkov ( I956) and Sweet (1960) have shown that most, if not all, of the rhyparochromines are seed feeders. Thus the function of these legs remains unknown. They do not appear to be used in mating behavior or in antennal cleaning, nor to any appreciable extent in carrying food etc. Yet it seems unlikely that legs of this type would persist throughout hundreds of species in many different genera distributed in several different subfamilies and in all of the major zoogeographic regions without having an important function. Solution of this problem should be a matter of considerable interest to those concerned with the question of correlation of form and function from inferred evidence. Recently Sweet (in litt.) has noticed some remarkable threatening behavior, displayed intraspecifically by several species of rhyparochromines in defense of food, that involves the use of the fore femora. This may offer a clue to an understanding of this interesting biological problem.

Despite our lack of knowledge of the function of these fore legs we do know enough of their occurrence in the family Lygaeidae to conclude that they are not of random distribution. The presence of incrassate fore femora is the predominant condition in the Rhyparochrominae, Pachygronthinae and Oxycareninae whereas they are

\footnotetext{
*Manuscript received by the editor December 20, 1961.
} 
absent or infrequently developed in the Lygaeinae, Orsillinae, Ischnorhynchinae and Geocorinae. Thus it can be seen that the presence of incrassate fore femora is at least roughly correlated with ventrally located spiracles. The latter is the less specialized condition. The correlation may well be more than coincidental and at least give some indication that an enlarged femur represents the generalized condition within the family.

It is thus most interesting to encounter a member of the Ischnorhynchinae with forelegs as strongly developed as in any of the subfamilies whose members are usually provided with incrassate fore femora. Except for the remarkable front legs this insect appears to be a conventional ischnorhynchine. It possesses dorsally located spiracles, a large claval commissure, a punctate clavus, hyaline membrane of the fore wing, hind wing with hamus and intervannals present, a "pruinose" body bloom, and a non-depressed posterior pronotal margin.

\section{Macellocoris new genus}

Fore femora strongly incrassate, armed below with four sharp, prominent, elongate spines; lateral margins of pronotum non-explanate but sinuate, bearing a series of prominent setigerous tubercles; clavus with a closely set row of punctures adjacent to claval suture and two inner rows of very large coarse punctures; membrane transparent, hyaline, exceeding apex of abdomen; eyes prominent, in contact with antero-lateral pronotal angles; apex of head attaining but not exceeding first antennal segment; preocular distance greater than eye length; lateral margin of corium explanate.

Type species: Macellocoris incrassatus new species.

Macellocoris incrassatus new species

Plate 2

General coloration reddish-brown, pronotum lighter on either side of midline posterior to calli and near anterior margin; hcmelytra opaque whitish, the irregular punctures brown; legs yellow with anterior femora bright tan; antennae with segment one, two except extreme apex, basal one-half of three and basal one-fourth of four yellowish with remaining antennal areas fuscous; venter reddish brown; mesal area of sternum black; head with large, coarse, contiguously placed punctures that give a rugose appearance; pronotum and scutellum with rather small, decp evenly spaced punctures; claval punctures very large and deep, those on corium irregular in size and 


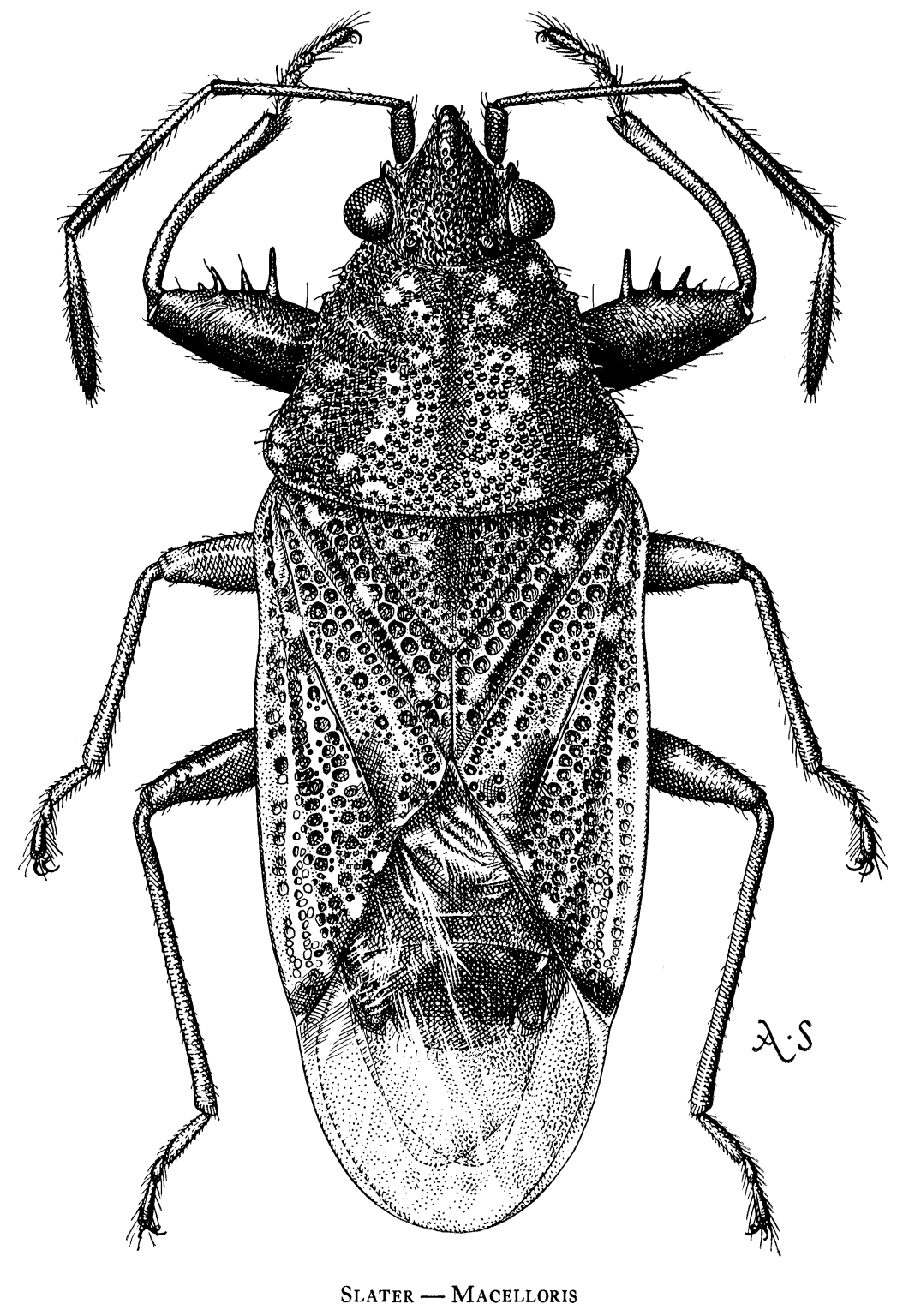


position with a definite row adjacent to the claval suture; surface nearly glabrous, head, pronotum and scutellum with short semidecumbent setae in the punctures; appendages sparsely but definitely pubescent.

Head non-declivent, moderately acuminate, tylus projecting well beyond the juga; first antennal segment about attaining apex of tylus; eyes large not produced, strongly in contact with anterolateral pronotal angles; length head $.70 \mathrm{~mm}$.; width across eyes $.85 \mathrm{~mm}$., interocular space $.48 \mathrm{~mm}$.; pronotum evenly narrowing anteriorly, lateral margins slightly sinuate, narrowly carinate, bearing 6-7 setose tubercles, transverse impression absent mesally but faintly indicated by depressed area near lateral margin, dorsal surface slightly convex becoming less so in area of calli and anteriorly, length pronotum 1.05 mm., width pronotum I.55 mm.; scutellum evenly tumid with depressed base, no median carina, length $.60 \mathrm{~mm}$.; corium with broad slightly upturned explanate margin, this laterally rounded becoming sinuate adjacent to apex of scutellum; apical corial margin sinuate, concave along basal one-third; distance apex clavus to apex corium I.IO mm., distance apex corium to apex membrane $.90 \mathrm{~mm}$.; membrane greatly exceeding apex of abdomen; distance apex abdomen to apex membrane $.75 \mathrm{~mm}$; ; middle and hind femora slightly enlarged, with basal one-fourth slender, giving a clavate appearance; labium elongate, attaining posterior margin of first abdominal sternite, first segment exceeding base of head, second segment extending onto anterior portion of mesosternum; length labial segments I .65 mm., II .62 mm., III .6o mm., IV .35 mm.; antennae slender, segments two and three terete, fourth segment narrowly fusiform; length antennal segments I .25 mm., II $.75 \mathrm{~mm}$., III $.82 \mathrm{~mm}$., IV .7O mm. Total length $4.65 \mathrm{~mm}$.

Holotype: Male. SUMATRA: Pematang Siantar, June 1937. (CT $\&$ BB Brues). In Museum of Comparative Zoology (Harvard).

\section{Acknowledgements}

I should like to extend my appreciation to Drs. P. J. Darlington and W. L. Brown (now at Cornell University), of the Museum of Comparative Zoology, for the opportunity to study this interesting

Explanation of Plate 2

Macellocoris incrassatus new species. Drawing by Arthur Smith, British Museum (Natural History). 
insect. Appreciation is also extended to the University of Connecticut Research Foundation for providing funds for the execution of the plate by the distinguished Arthur Smith of the British Museum (Natural History).

\section{Literature Cited}

Miller, N. C. E.

1956. The biology of the Heteroptera. Leonard Hill Ltd: London. Putshkov, V. G.

1956. Basic trophic groups of phytophagous hemipterous insects and changes in the character of their feeding during the process of SWEET, M. H. development. Zcol. Zhur. $35:($ N. 1) :32-44.

1960. The seed bugs: a contribution to the feeding habits of the Lygaeidae. (Hemipt. Heter.) Ann. Ent. Soc. Amer. 53:317-321. 

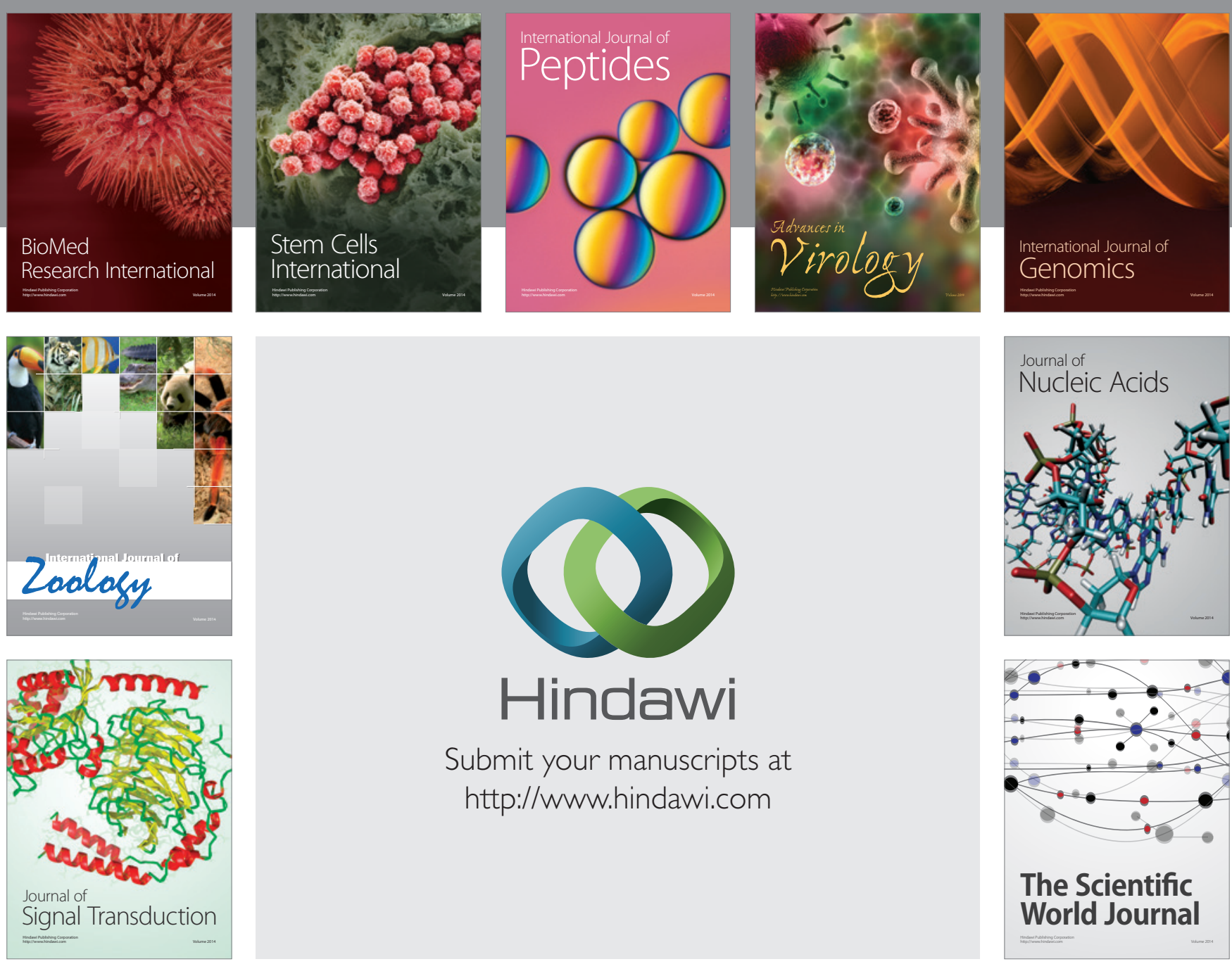

Submit your manuscripts at

http://www.hindawi.com
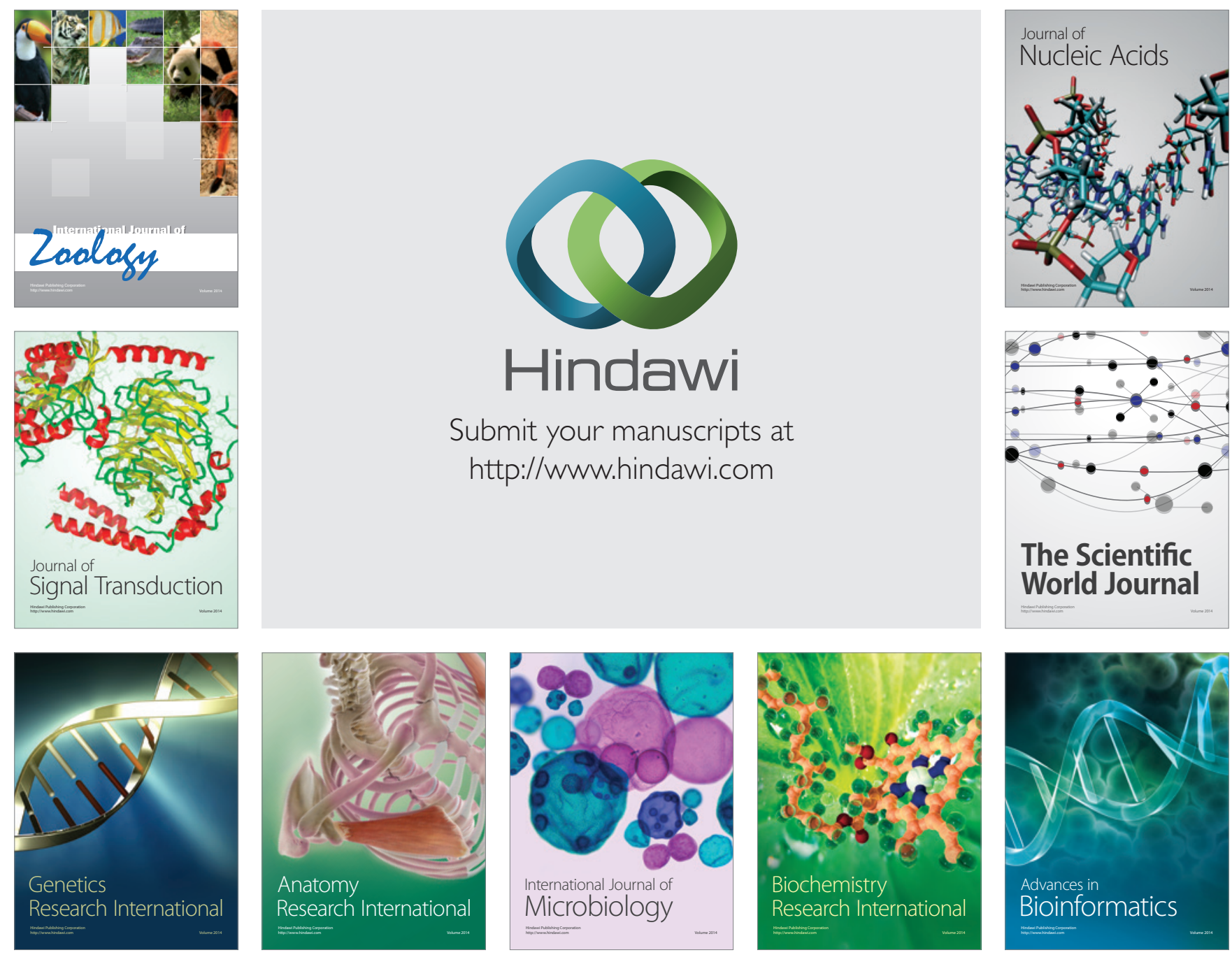

The Scientific World Journal
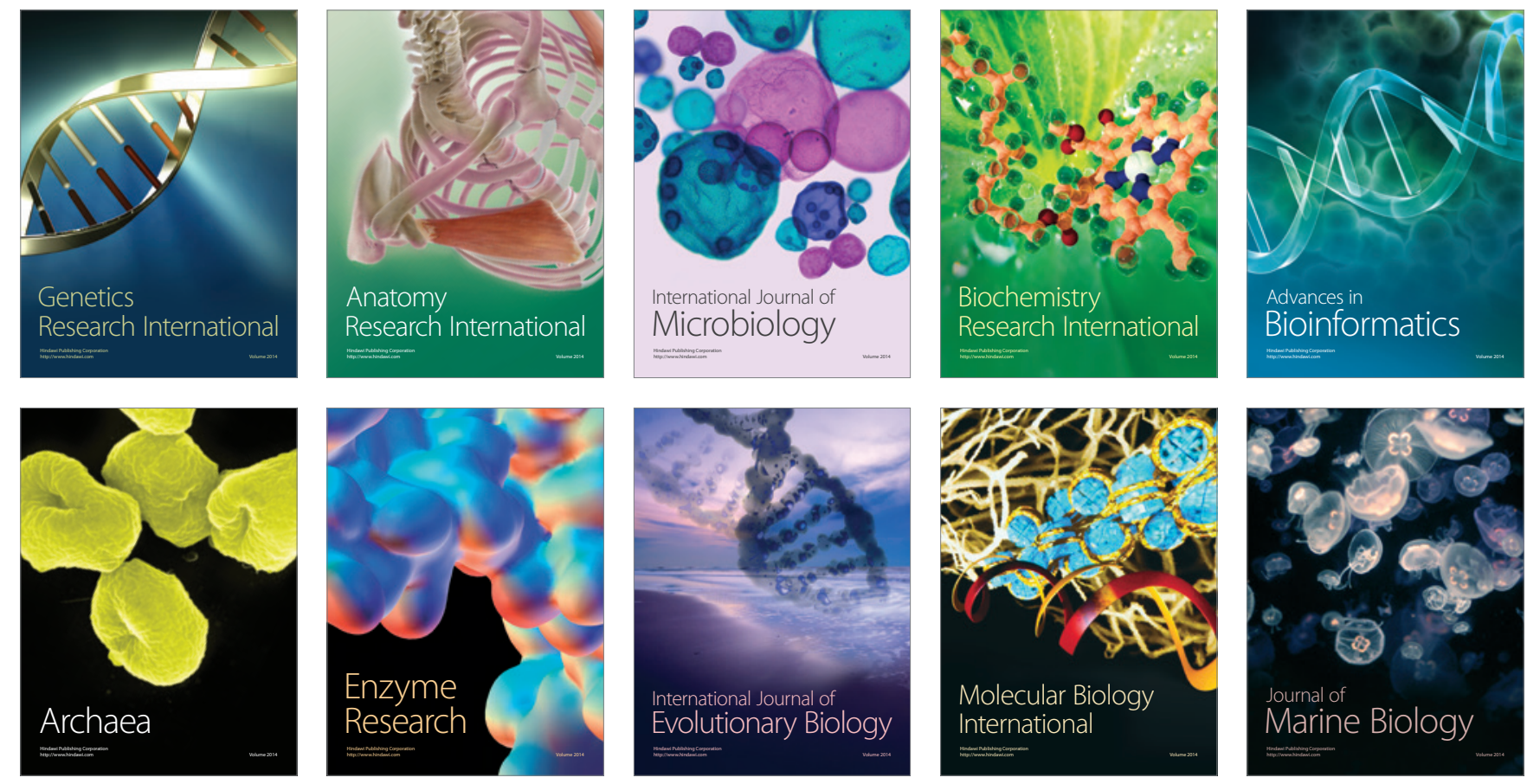